\title{
Sexual health dialogue between parents and teenagers: An imperative in the HIV/AIDS era
}

\author{
RT Lebese, D Cur \\ Lecturer Department of Advanced Nursing Science University of Venda \\ M Davhana - Maselesele, D PhiL \\ Dean, Faculty of Agriculture; Science and Technology North West University (Mafikeng Campus) \\ CL Obi, PhD \\ Deputy Vice-Chancellor Walter Sisulu University
}

\section{Key words}

Sexual health, dialogue, teenagers, parents, HIV, AIDS

\section{Correspondence address}

Dr Rachel Labese

University of Venda

Department of Advanced Nursing Sci-

ence

P/Bag X5050

Thohoyandou

0950

Tel : (051) 962-8393

Fax:0866190062

Email: Rachel.Lebese@univen.ac.za

\begin{abstract}
Curationis 33 (3): 33-42
Societies are reluctant to openly confront issues of sexuality, and this reluctance forms a barrier of communication between parents and teenagers and even between sexual partners (Wulf, 2004:2). This reluctance promotes the presence of misconceptions about sexual health, sexual risks and its consequences. Poor dialogue about sexual health between parents and teenagers is one of the contributory factors of high teenage pregnancy and sexually transmitted infection (STI) rates including HIV and AIDS.
\end{abstract}

The purpose of this study was to explore and describe how dialogue about sexual health between teenagers and parents is conducted and to use the information gathered as a basis for making recommendations for improvement.

A qualitative study of an explorative, descriptive and contextual nature was used. The researcher used the main question as a point of departure and more questions emanated from the discussions. There were 42 informants involved in the study, of which 4 were males and 38 were females. A purposive sampling method was used to collect data through in depth individual interviews and focus group discussions. The researcher strived to adhere to the principle of trustworthiness by adopting Guba's model (in Krefting, 1991: 217). Tech's method (Creswell, 1994: 154-55) was used to analyse the data and an independent coder was used.

The results indicate that there is minimal if not absent dialogue about sexual health between teenagers and parents. Culture was identified as a major challenge to sexual health dialogue between teenagers and parents. Recommendations to enhance dialogue were made. 


\section{Introduction and background}

Society's reluctance to openly confront issues regarding sexuality results in a number of untoward effects. This social inhibition stands in the way of communication between parents and children and between sex partners. This results in poor development and implementation of effective sexual health and HIV/AIDS education programme (Wulf, 2004:2). This reluctance also perpetuates misperceptions about individual sexual risks and ignorance about the consequences of taking risks and may encourage high-risk sexual practices. The silence that is experienced within communities about sexual health is also experienced within families and schools (Wulf, 2004:2).

Most parents and teachers talk to their children by giving orders or correcting them. This approach makes children learn to give orders and criticise and not to spend time in non-threatening conversation that helps people to understand one another (Wulf, 2004:2). Many children are said not to remember conversations with parents that were non-threatening; that is conversations where their parents were not telling them what to do or what they did wrong. Parents are said not to ask children about their opinion (Wulf, 2004:2). This indicates that there is a need for parents to engage their children in dialogue, where both parties contribute equally to the conversation since dialogue is valuable in helping family members understand and appreciate one another.

The lack of dialogue about sexual health between teenagers and parents especially in rural areas, is a matter of concern especially because of the HIV/ AIDS epidemic, and the prevalence of sexually transmitted infections (STIs). Teenage pregnancy is another major problem as the prevalence is escalating each year (McCormick, 2004:4). Globally, it is estimated that over 33 million cases of sexually transmitted infections occur each year. Out of this number more than $50 \%$ is reported among the youth (McComick, 2004:4). Teenage pregnancy is also high among teenagers worldwide, with about one million teenagers becoming pregnant each month and $33 \%$ of them terminating the pregnancy (McCormick, 2004:4). The high number of teenage pregnancies may be attributed to the fact that teenagers have little access to free confidential family planning, little communication with their parents and lack of knowledge regarding contraception by parents. Low educational aspirations might also be the cause of high teenage pregnancy rates in the rural areas (Hopkins, 2000:16). In the study conducted by Maja (2007:75) about the involvement of males in promoting reproductive health, a significant number of males were found to have knowledge about contraceptives including condoms. However, this knowledge did not influence the use of these methods to prevent unplanned and unwanted pregnancies. The following reasons were given for not utilising the condoms: partner trust; diminished sexual satisfaction; condom breakages; and lack of skill in using the condoms (Maja 2007:75).

Cultural beliefs and attitudes also determines how teenagers relate to their parents, teachers and elders in the community and it dominates the way of life in the rural areas. Values and norms guide what can be discussed between different age groups (Mfono, 1998:124). Therefore, the extent to which issues of sexual health are discussed between different age groups is also determined by their cultural practices. Mfono (1998:36) mentioned the difficulties that parents experience in communicating with their children about sexual matters. Parents usually do not see their children as grown-ups who are ready to discuss or contemplate sexual involvement. It has also been discovered that the information parents give to their children regarding sexual matters is too inadequate to equip teenagers to face the pressures related to sexual matters (Mavundla \& Williams, 1999: $62)$.

The study conducted by Kempner (2003:5) revealed that adults were uncomfortable about adolescent sexuality and often try to ignore the fact that their teenagers are sexual beings who engage in sexual behaviour. Teachers were reported to be experiencing discomfort during sexuality education in the classroom as sexuality education is viewed as encouraging sexual behaviour and experimentation among teenagers. At the same time, adults are said to be aware of the high levels of STI's and pregnancy among the teenagers and the need to intensify sexuality education (Kempner, 2003:6). Cultural practices also impact, to a certain extent, on the degree to which information about sexual health is communicated to teenagers, especially in rural areas. Initiation schools also do not give teenagers enough information about sexual health as most of the time, teenagers are expected to recite poems and songs (Mfono, 1998:124). Hence it is necessary to promote dialogue about issues of sexual health with teenagers, as sexual health knowledge is vital in preventing sexual health problems.

Ingham and Stone (2002:51) described how important it might be for parents to equip their children with skills to communicate and interact effectively with future sexual partners. Parents' willingness and ability to discuss sexuality openly and positively throughout their children's lives appear to impact both competence and confidence in their children (Ingham \& Stone, 2002: 55). In contrast, reluctance to talk about sexual matters and embarrassment in doing so, may reinforce negative messages of unacceptability and prohibition (Ingham \& Stone, 2002: 56).

\section{Problem statement}

Vhembe District in Limpopo Province is plagued by a high rate of sexually transmitted infections including HIV and AIDS and pregnancies among teenagers with a marked decrease in the use of contraceptives. The high rate of teenage sexually transmitted infections, pregnancies and termination of pregnancies might be indicating that the methods employed to address sexual health do not reach teenagers or may not be effective.

Therefore one might assume that teenagers are not getting enough information about sexual health and healthy sexual behaviour. Lack of knowledge exposes teenagers to sexually transmitted infections including HIV/AIDS, teenage pregnancy and early parenthood. It is, therefore, necessary to explore and describe how parents as primary educators of their children engage teenagers in sexual health dialogue.

\section{Research questions}

The study sought to address the following questions: 
How do parents engage teenagers in sexual health dialogue?

- What are the implications of cultural practices that exist in relation to sexual health dialogue between teenagers and parents?

- What recommendations can be made in relation to sexual health dialogue between parents and teenagers?

\section{Purpose of the study}

The purpose of this study is to explore and describe how dialogue about sexual health is conducted between teenagers and parents in Vhembe district. Information will be used as a basis for making recommendations for improvement.

\section{Objectives of the study}

The objectives of the study are as follows:

- $\quad$ Describe the way in which parents engage teenagers in sexual health dialogue.

- $\quad$ Identify and describe the implications of cultural practices that exist in relation to sexual health dialogue between teenagers and parents.

- $\quad$ Make recommendations in relation to sexual health dialogue between parents and teenagers.

\section{Significance of the study}

This study will uncover some sociocultural perspectives influencing sexual health dialogue among teenagers and parents and identify how such dialogue is initiated; strategies to improve such dialogue will also be described.

Dialogue about sexual health would eventually lead to a reduction in the rate of sexually transmitted infections, teenage pregnancy and termination of pregnancy and increase the use of reproductive health services. It is also expected that findings will inform sexual and reproductive health policy review and implementation.

\section{Meta-theoretical assumptions}

The researcher's point of departure is the assumption that teenagers are human beings with sexual needs, which need to be fulfilled. Teenagers are also unique beings who can make their own choices. Teenagers need to make informed decisions regarding the fulfillment of this need. Education of teenagers about sexuality, particularly by parents, is of vital importance in assisting them in making informed decisions about sexuality. The researcher believes that primary socialisation of children starts at home where parents have a role of educating their children about issues of sexual health. The teenagers will then internalise what they have been taught and this will determine the decisions that they make about their own sexual health.

\section{Theoretical assumptions}

The study was conceptualized within Leininger's Sunrise Trans-Cultural Health Care Model (Leininger, 1991: 30). The model takes into consideration individuals and groups, their beliefs and value system. These specific cultural practices form the basis or the means through which the delivery of satisfactory health care to the people can be accomplished. The goal of this theory is to provide cultural congruent care. Leininger states that if one studies the meanings, forms and expressions of cultural care, one might understand care better and predict the health or well being of individuals and families. The author further contends that from the client's worldview, social structure component and environmental factors, three modes of culture care decisions and actions can be predicted to guide nursing care. The three modes are: cultural care preservation or maintenance, cultural care repatterning or restructuring and cultural care accommodation (Leininger, 1991: 30). Through the use of Leininger's Sunrise Model the researcher can determine meanings attached to how dialogue about sexual health is conducted between teenagers and parents and make recommendations using the three modes of cultural care decisions as described by Leininger.

\section{Methodological assumptions}

Methodological assumptions are concerned with the nature and structure of science of research, and include the preferences and assumptions of the research (Mouton, 1996: 124; Mouton \& Marais, 1990: 20). A functional approach is envisaged for this research because the information gathered will assist parents in identifying problem areas related to the way they engage teenagers in dialogue about sexual health. The involvement of teenagers in sexual health dialogue will assist them in making informed decisions about sexual health. This will increase the use of contraceptives by teenagers; reduce the rate of sexually transmitted infections including HIV and AIDS, teenage pregnancies and parenthood and termination of pregnancies The results may also inform policy review and implementation.

\section{Operational definitions}

\section{Teenager}

In this study a teenager will be a male/ female from the age of 10-19 years who is attending school and has a relationship with a person of the opposite or same sex.

\section{Parent}

A parent in this study is any person who is a parent to a child of 10 to 19 years or a parent to a child who has given birth during teenage years or a parent to an HIV positive teenager.

\section{Dialogue}

In this study dialogue will be a twoway conversation between teenagers and teachers or teenagers and parents about sexual health.

\section{Sexual health}

Sexual health is the ability to express one's sexuality free from the risk of sexually transmitted infections, unwanted pregnancy, coercion, violence and discrimination. It means being able to have an informed, enjoyable, and safe sex life, based on a positive approach to sexual expression and mutual respect in sexual relations.

\section{Research approach and methods}

A qualitative, explorative, descriptive and contextual approach was used for this study. The study strove to explore the phenomenon from the perspective of teenagers and parents. People were studied in their natural setting in order to discover the social world of cultures and languages by observing and talking to them (Halloway \& Wheeler, 1996:17). The researcher also used one 
central question as a point of departure and more questions emanated from the discussion. Informants narrated their experiences and these experiences were captured in words and quotations were used to emphasise various aspects that were described (Burns \& Grove, 2001:61; Kvale, 1983: 175; Polit and Hungler, 1995: 50). The experiences of parents were explored and then described within the context of the rural villages of Vhembe District in Limpopo Province, South Africa (Brink, 2000: 11; Burns \& Grove, 2001: 79-95; Mouton \& Marais, 1990: 43, 44).

\section{Population and sampling}

The population for this study included all parents to teenagers in Vhembe District of Limpopo Province (Brink, 2000: 132). Villages with high statistics of teenage pregnancies and sexually transmitted infections were sampled. A purposive sample of parents who had teenage children or teenagers who had given birth in their teenage years were sampled from all villages. There were 42 informants involved in the study, of which 4 were males and 38 were females. (Brink, 2000: 141). The size of the sample was determined by data saturation when no new information did not come up and started to repeat itself.

\section{Data collection}

The researcher collected data through in-depth individual interviews and focus group discussions. Participants in an in-depth interview were 11 (eleven) and 31 (thirty one) in a focus group discussion. Two focus groups had 10 (ten) and the third group had 11 (eleven) participants. In-depth interviews were conducted first as the researcher thought that more sensitive information can be elicited as the interaction is more private. Focus groups were done after the in-depth interviews and were conducted to allow the researcher to observe how the informants were willing to give information as this could also support the freedom that they engage other people on issues of sexual health. Permission to participate in the study was sought and the informed consent form was signed. Data was audio recorded; field notes and observational notes were taken. One central question that directed both interviews was: Can you please tell me your experiences of sexual health dia- logue with your teenage child? This question was translated to Xitsonga to make it easier for the informants to understand and participate. One question was used for both interviews as the researcher used paraphrasing and probe follow to deepen the discussions.

\section{Data analysis}

Data analysis was done simultaneously with data collection (Creswell, 1990:142). Data was transcribed and then translated verbatim from Xitsonga to English by a language practitioner. Recorded information was also compared with transcribed data to avoid omissions. Analysis was done according to Tesch's (in Creswell, 1990:142) eight steps of analysis. Literature control was done to ensure that there is a good fit between data and relevant literature, thus providing a link between previous research and the present research (Mdluli, 2005: 50).

\section{Trustworhiness}

Measures to ensure trustworthiness were applied in accordance with Guba's model in (Lincoln \& Guba, 1985: 290327). The key aspect to the model are the strategy of credibility, transferability, dependability and confirmability. Activities in achieving credibility included member checking, prolonged engagement, reflexivity, data triangulation and peer review. Transferability was obtained by using purposeful sampling working contextually and using dense description. Dependability was achieved by thick description of methodology (data collection and analysis and interpretation). Confirmability was achieved by auditing the entire research process, reflexive analysis and triangulation.

\section{Ethical considerations}

The researcher sought permission to conduct this study from the following different institutions:- Department of Education and Culture, the chiefs in the villages where data was collected and School Governing Bodies. Ethical clearance from the University of Venda was also sought and an oral presentation to the university ethics committee was done. Permission was also sought from the informants through an informed consent. Use of the audio tape and re- search assistant was also explained to them and they were also shown a stop button so that they could stop the recording wanted to stop the recording of certain information. The consent form was translated into Xitsonga to assist informants to gain more information as well as make it easy for them to understand. Informants were also informed about voluntary participation as they were made aware of the fact that they were free to terminate participation in the study without fear of being punished. Community entry was negotiated by the researcher and the research assistant this ensured that protocols related to Vatsonga was adhered to. This was easily facilitated as the researcher and the research assistant are from the same cultural group.

Private information of informants was not shared without their knowledge or against their will. The researcher ensured that the informants did not lose their dignity. Informants were made aware of the use of the audiotape as well as the presence of the research assistant. Confidentiality was ensured by not allowing people access to raw data. Participants' names were treated anonymously by using code names during interviews and the filling of raw data.

\section{Description of the sample}

Eleven (11) parents were involved in the in-depth individual interviews whist thirty -one (31) were involved in focus group discussions which were conducted three (3) times. The ages of parents ranged from 40 to 55 years of age. All informants who participated in in-depth individual interviews were not included in focus group interviews because the researcher felt that their interviews were long and any further involvement in the study would disrupt their daily activities. The size of the sample was determined by data saturation in each village. Three major themes as well as categories and sub-categories were identified from the data collected from parents.

\section{Discussion of the findings}

\section{Theme: Parents expression of events that motivate them to}




\begin{tabular}{|c|c|c|}
\hline THEMES & CATEGORIES & SUB-CATEGORY \\
\hline \multirow{3}{*}{$\begin{array}{l}1 \text { Parents' expression of events } \\
\text { that motivate them to engage } \\
\text { teenagers in a dialogue about } \\
\text { sexual health }\end{array}$} & $\begin{array}{l}\text { Physical development of teenag- } \\
\text { ers }\end{array}$ & $\begin{array}{l}\text { Development of breasts and curves } \\
\text { Starting to menstruate and breaking of the voice in } \\
\text { males. }\end{array}$ \\
\hline & $\begin{array}{l}\text { Changes in teenager and friends' } \\
\text { behaviour }\end{array}$ & $\begin{array}{l}\text { Identifying that the teenager is starting to be more } \\
\text { conscious about his/her appearance. } \\
\text { When another child within a family or close friends } \\
\text { becomes pregnant. } \\
\text { Observations made when children play specific } \\
\text { games eg. Mbilumbilu. } \\
\text { Teenagers' who cannot look you in the eye after } \\
\text { coming back late at night. }\end{array}$ \\
\hline & Media influence & $\begin{array}{l}\text { After hearing talk on radio/television or reading a } \\
\text { pamphlet about HIV/AIDS }\end{array}$ \\
\hline \multirow[t]{3}{*}{$\begin{array}{l}2 \text { Parents' expressions of how } \\
\text { they talk to teenagers. }\end{array}$} & $\begin{array}{l}\text { Parents expectations after talking } \\
\text { to their teenagers about sexual } \\
\text { health }\end{array}$ & $\begin{array}{l}\text { Take the advice they give them. } \\
\text { Not to fall pregnant or make a girl pregnant. } \\
\text { Boys making use of condoms that are given to them } \\
\text { by parents. } \\
\text { Teenagers accepting it when they accidentally fall } \\
\text { pregnant. }\end{array}$ \\
\hline & $\begin{array}{l}\text { Use of indirect speech by parents } \\
\text { when talking to teenagers. }\end{array}$ & $\begin{array}{l}\text { Girls should not play with boys as this can destroy } \\
\text { their youth. } \\
\text { Menstruation is referred to as big bilharzias. } \\
\text { Girls should not run around with boys as they will } \\
\text { become pregnant. } \\
\text { A girl should not stay with boys. } \\
\text { After developing breasts there is something that is } \\
\text { going to surprise you. }\end{array}$ \\
\hline & Avoidance behaviour & Going to sleep or switching off television \\
\hline $\begin{array}{l}\text { 3. Factors that are seen as con- } \\
\text { tributing to teenagers' promis- } \\
\text { cuity }\end{array}$ & Contributory factors & $\begin{array}{l}\text { Explicit sexual information from school } \\
\text { Listening to radio } \\
\text { Peer influences. } \\
\text { Watching television }\end{array}$ \\
\hline
\end{tabular}

\section{engage teenagers in a dialogue about sexual health}

Parents also expressed how difficult it is for them to initiate dialogue with teenagers. Almost all parents interviewed, pointed out that dialogue about sexual health with teenagers is initiated as a reaction to specific things or occurrences. Occurrences that were identified as stimulators of sexual health dialogue are:

- $\quad$ Physical development of teenagers

- $\quad$ Changes related to the lifestyle

\section{of a teenager}

- $\quad$ Media influence

\section{Physical development of teenagers}

Observations on physical and physiological changes ranked high as stimulants for initiating a discussion. Most of the participants said that they usually observe their children for physical changes in their bodies which indicate that the child is physically ready for reproduction. These developments were indicators to them that the child has grown and can fall pregnant or make somebody pregnant.

\section{- Development of breasts, starting of menstrual periods and breaking of the voice in males}

One informant said 'You know it is so difficult for a parent to talk to a child about issues of sex, especially us blacks who were taught that this is taboo. When I realised that my daughter had developed breasts and that she wanted me to buy her a bra I thought that was a good opportunity for me to start talking to her about sexual 
health. I am telling you, it was so difficult. I could not look her in the eye.'

One informant said 'This is a difficult subject to have with my daughter. I kept on asking her if she has not seen something on her panty. I could not even tell that this something is blood. I could not speak out that word. I also believe my girl was confused as well. The day that she saw this thing she came and said she was sick and when I was talking to her I ended up knowing that she had started menstruating. This was teaching by trial and error and it's not appropriate I think we need to be open, you know you want to but you are unable to bring out the words it is sooo!!!!!!!!!! difficult'.

Another informant said' my teaching was reactionary. One day when I was changing her bed linen, I discovered spots of blood on the sheet. I called her and asked what these sports were. She was very shy to explain and she started crying. I then told her that if she sleeps with boys she will be pregnant'.

Another informant said 'With my elder daughter, it started when she had her first menstruation. I had never talked to her about issues of sexual health or even developmental changes that she was going to experience in her body. You know it caught me by surprise. One day if I can still remember it was summer she came back from school before time and was crying saying that she was in pain. She slept the whole day. The following morning when I was making her bed I realized that her linen was soiled with blood. I called her in and asked her what was happening. I was very harsh with her and demanded an explanation. She never replied she just cried. I was also frightened not knowing what to tell her. I just gave her sanitary pads'.

Direct quotes from parents indicate that breast development, development of curves, menstruation and breaking of the voice are some of the signs that the parents use as a basis for talking to teenagers about sexual health. This can be a misleading sign as in some teenagers' breasts do not develop as expected whilst in others, especially those who are overweight, breast tend to develop early. In a study conducted in North Carolina by Brown, Halpern and Engle (2005: 425) it was discovered that early maturation of girls is linked to more interest in seeing sexual content movies, television and magazines than late maturing girls. In the light of this research, it can be concluded that parents might be right in linking physical development and readiness to the commencement of educating their children about issues of sex. Maturing girls might as well interpret the messages they see in the media as approval for having sexual intercourse (Brown, et al, 2005: 425).

The parent's way of teaching is an indication that parents themselves are always on the lookout for these physical development changes so that they can initiate dialogue with their children. It is also assumed from these descriptions that most of the parents do not want their children to fall pregnant before time. If this is true, it means that they have a need to educate their children about sex but they just do not know how and when. This model that is being developed will then help them to initiate dialogue. There is also need to educate parents about these physical developments so as to enable them to teach their children before they experience it. Parents need to be more proactive than reactionary in their sexual health education.

\section{Changes related to the lifestyle of a teenager}

Observations are also made by parents on the behaviour of teenagers and their friends. Participants indicated that the following are indicators for readiness to initiate dialogue with teenagers:

\section{- $\quad$ Change in behaviour of teenagers}

One informant said 'As a parent I need to be observant about what is happening around my child. You know it is easy to identify when your child has started to be naughty. When a child bathes a lot and wants to be neat at all times, it means there is somebody who this child of mine is trying to attract or look smart for. There and then one should question this child about the new image change and warn him/ her about the dangers of dating'.

Another informant said 'I always observe the type of friends that my girl has and I believe in the saying that says birds of the same feathers fly together. If my child's friend is seen with boys or is pregnant, this should be a warning sign for a parent. This might mean that my child is also doing the same things. So as a parent, I start talking to my child there and then. You know, one of her best friends fell pregnant and I just told her point blank that I will never tolerate it if she goes around sleeping with boys. I will never allow her in my house if she falls pregnant as she can see that I am poor'.

Another informant said 'I started warning my daughter about boys when I discovered that her friend has given birth'.

Another informant said 'Tell me where does a child go to when its dark at night? When my son started going out late and coming back after midnight, I knew that he was sleeping around. So because of HIV and AIDS I took condoms from the clinic and I gave them to him. Every now and then I check them and you find that they are finished meaning that he is using them. This has helped because no girl has been brought to my house because he has impregnated her'.

Another informant said 'These children are free when they are with us and you are just discussing general things with them but when you start talking to them about sex or try to find out why they are always coming home late, you will find that these children cannot look you in the eye. Then you must know that he/she has started sleeping around and this is normally accompanied by aggression. You end up not knowing what to do as a parent'.

Participants describe how the teenager always wants to be neat and well groomed. They indicated that when a teenager bathes a lot, parents should start suspecting that they have now started to have relationships with people of the opposite sex. Participants felt that if a child starts to bath a lot and change clothes, it means that that child wants to be attractive to the opposite sex and this is said to be a warning sign that the teenager has started dating. Parents also said they observed how girls play with boys as this gives them an indication of whether they have started dating or not. This gives them 
the opportunity to warn teenagers about the dangers of dating.

Participants also explained how they use the character of their children's friends as indicators for the need to start to talking to their teenagers about sexual health. The teenagers are usually warned about such behaviour and the consequence of such behaviour is indicated to them.

Teenagers were also said to be shy when you talk to them especially when they have already started to have sex. Participants describe how the teenager will not look them in the eye when they have started having sexual intercourse. This is said to be caused by the fact that teenagers know that having sex before marriage or at that age is wrong. Participants also indicated that they also start talking to the teenagers when they observe that they like going out late at night and coming back late or in the morning. It is when they are addressing this fact that they start talking to them about sexual health. This is because it is assumed that the person who goes out at night is visiting a sexual partner. Other problems like drug abuse can easily be overlooked.

The difficulties in initiating dialogue that are expressed by parents are also expressed by physicians in the study by Hassan and Creatsas (2000: 121) who also indicated that physicians felt ill equipped to counsel adolescents on issues of sexual health. Teenagers also reported that they have never been asked by the physician about sexual issues even if the physicians knew that they are sexually active. On the other hand, in the study conducted among Costa Rican teenagers, parents were quoted as important sources of information (Stycos, 1987:4). In another study by Muller and Powers, (1990: 457) the communication style between parent and child if perceived as friendly, attentive and open, was seen as having a positive influence on the use of contraceptives by teenagers. Participants indicated different aspects that motivate parents to talk with teenagers about sexual health. In contrast, research suggests that parents' attitude towards sexual health education is associated with abstaining from sexual intercourse and delaying initiation of sexual intercourse (Mueller, Gavin \&
Kulkarni 2008: 93). It should however be noted that some studies identified that girls can successfully hide behaviours that they think their parents will not approve of (O’Donnell, Stueve, Duran, Myint-U, Agronick, Doval \& Wilson-Simmons 2008:501).

The researcher noted with concern that it is not easy for parents to initiate a dialogue with their teenage children. Parents tend to wait for a specific behaviour indicators and physical changes in their children to start to talking to them about sexual health. This might mean that sexual education is not given priority as it should be. Negative perceptions towards dating and being with boys can also be built in the teenager as parents associate dating and being with boys as something that is bad and should not be done. The labeling of friends that are dating or that have delivered can also mean that dating and giving birth is wrong and teenagers might opt for termination of pregnancy should they fall pregnant. Parents should approach this topic with tact and introduce it early in life. They should gradually deepen the discussions as the children grow. Dialogue about sexual health should involve more than just warning teenagers about the dangers of sexual intercourse. It is important to give them adequate information so that they can enjoy sexuality whilst taking necessary precautions.

\section{Media influence}

Media was also cited by participants as another major stimulant of dialogue about sexual health between them and teenagers. The following is one major influencer of dialogue through the media:

\section{- Radio or television talks on HIV and AIDS}

One participant said 'Television and radio talks help us a lot because I normally take that occasion after these talks to talk to my teenage children about sexual issues. It is easy you know because you just follow up from the discussions that were in the media'.

'One day I was so shocked about the type of pictures that I found in the book that my son was having. The book consisted of all positions of having sexual intercourse that one can think of. I could not even confront him about this I was too ashamed I did not know where to start'.

Participants also indicated that most of the time dialogue is easily initiated after listening to radio or television about HIV and AIDS. It is then that this talk is used as a starting point. They explained how easy it is for them to initiate a dialogue as they just continue from what has been discussed on radio. Radios were said to be very informative but the problem that was expressed is that most of the times they teach bring these lessons when these children have gone to school. This sometimes makes it difficult for them to restart a discussion. Participants also indicated that they sometimes get magazines that are too explicit in the rooms of their teenagers and this tends to worry them.

Studies indicate that parents stimulate a discussion about sexual health when travelling by car, during a television show or when buying a book which they will discuss after the teenager has read the book (Eastman, Corona, \& Schuster, 2005:66). This is an indication that parents talk about sex passively with their children as this topic is not given proper attention. In a study conducted in North Carolina, it was also discovered that parents' level of education has an influence on sexual health education at home. It was also revealed that parents who are educated preferred to teach their children as they believe that they have sufficient information (Kristen, Gizlice, Foust, OwenO’Dowd \& Miller, 2006: 634). Participants also indicated that most of the time dialogue is easily initiated when or after listening to a radio or television programme about HIV and AIDS. It is then that this talk is used as a starting point.

One might, therefore conclude that lack of interest and knowledge identified in the study is mainly because most parents in the villages are illiterate and therefore do not have sufficient information to teach teenagers. The researchers also noted that there is no dialogue about sexual health between teenagers and parents. Teenagers are just warned about the dangers of dating and the warning does not give teenagers enough information to make a decision about their sexual health. This is evidence enough that there is no dia- 
logue about sexual health as parents tend to warn or tell teenagers what to do and teenagers are not given a chance to bring in their views. The researchers also noted that most parents talk about the dangers of falling pregnant and other important issues of sexual health are not addressed.

\section{Theme: Parents' expressions of how they talk to teenagers and their expectations}

From the data collected from parents it has been identified that parents have a way of talking to teenagers and they also have certain expectations after talking to them. The following are the two categories that have emerged in relation to the parents' expectations and how they talk to teenagers:

- $\quad$ Parents' expectations after talking to teenagers

- $\quad$ Use of indirect speech by parents when talking to teenagers

\section{Parents' expectations after talking to teenagers}

One informant said 'I normally advise my son to use a condom when engaging in sexual intercourse and I sometimes bring them home for him to use, but to my surprise he has made a girl pregnant'.

Parents indicated that they have certain expectations after talking to teenagers about sexual health. They indicated that all the time they expect that teenagers should take their advice and not fall pregnant. It is also surprising why parents tend to rely on these discussions when they were not dealt with intensively. This is an indication of the extent to which these teenagers are being engaged in a dialogue. The dialogue is very minimal or absent hence they do not adhere to what they are told. It is also possible that teenagers do not adhere to parental advice as parents tend to tell them what to do and how to behave. O'Donnell, et al, (2008: 501) identified in their study that girls who report that their parents oversee their activities, set rules and communicate disapproval of risky behaviour are less likely to engage in alcohol use, disapproved conduct and early heterosexual behaviours related to early sexual initiation.

\section{Use of indirect speech by parents when talking to teenagers}

One informant said 'When my daughter started menstruating I just called her and told her that now that you have this big bilharzias, you should not run around with boys as you will become pregnant'.

Another informant said 'When she came back I just told her that from that time onwards she is not supposed to play or sleep with boys as this will make her pregnant. I could see that she was confused but there was no other way to tell her. When the other girl started menstruating the same approach was used but I was not fortunate with my second daughter because she fell pregnant and she has a baby now. My son also impregnated another girl who is still pregnant as she has not yet given birth. I am also worried about 'AIDS' as this means they are not practicing safe sex. But how do I tell them? yooo!!!!!!! it is a problem'.

\section{Avoidance behavior}

One informant said 'When a movie on television shows people kissing, cuddling or having sexual intercourse, I immediately go away to sleep, go and do something else or switch off the television. I feel so much embarrassed by the whole thing. With my son I think the person responsible for his sex education is my husband, but I also think that the school should teach them more as long as they are not explicit in their explanation. If the teachings are explicit it will influence them to want to experiment'.

Another informant said 'I sometimes get shy and go to sleep when I am busy watching television with my children and you start seeing people kissing and having intercourse. I can't watch these things with my children so I just go to sleep or ask them to switch off the television'

During interviews it was also identified that parents make use of indirect speech when they talk about sex with children and this usually leads to misinterpretations. Most of the parents interviewed refer to menstruation as big bilharzias. This can be misleading to teenagers as these are not the same thing. Parents do not address teenagers in a way that they will end up knowing what they are expected to do. An explanation of what is happening in their bodies when they menstruate is not given. It is also worrying that parents can not say directly what will happen after these girls have started menstruating. This therefore, means that if the girl has sex with a boy it is not a problem; the main problem as advised by parents is playing with them or staying with them. This could be very difficult for a teenager to understand as the parent was not direct in her speech. It has also been noted that parents always talk about avoidance of pregnancy and emphasis is not placed on other sexual health issues. It is, therefore, important that parents start addressing all issues of sexual health.

Wood, Maforah and Jewkes (1998: 237) in their study indicated that teenagers reported that they were not given information about reproductive matters by their mothers beyond the warning of saying that when they start menstruating they must stay away from boys as intergenerational transmission of sexual information was taboo. In Thailand girls were said to be dating without parental support and life skills of negotiating coercive situations (Vuttanont, Greenhaigh, \& Boyton, 2006: 2079).

The importance of school, peer and parents support of positive behaviour was found to be important in reinforcing positive lifestyles of teenagers (He, Kramer, Houser, Chomitz \& Hacker, 2004: 30). Parents should realise the importance of the role that they play in informing their children about sexual health. This will reduce the risks of abuse and contracting sexually transmitted infections.

Participants also indicated that teenagers' promiscuity is also influenced by the type of peers that they associate with because teenagers tend to copy what their peers do most of the time. One parent during an interview said 'If your daughter goes around with people who do not have manners, she will be influenced and start behaving like them'. Participants also believe that explicit sexual information that teenagers get from school tends to influence them to become promiscuous as they will go around experimenting. 


\section{Factors that are seen as contributing to teenager's promiscuity.}

One informant said 'Yooo!!! Television is dangerous. Our children watch it the whole day and some of the things that are shown there are embarrassing. Every time somebody is kissing a girl or trying to have intercourse with a girl. It is embarrassing how can one watch these things. I even blame myself for having bought the television, uuu!!! It is disgusting'.

Parents believe that different factors such as access to radio and television contribute to teenagers' promiscuity. Participants believe that teenagers tend to copy what they see on television, especially because everything is done publicly. This is an indication that sexual health dialogue is not possible as the parents are not at ease with the subject.

Brown, Halpern, and Engle (2005: 5) confirmed in their studies that adolescents who frequently visit sexually explicit web sites are more likely to engage in high-risk sexual bahaviours such as multiple sex partners and using substance abuse during sex. These adolescents are also said to have sexually permissive behaviour and readily indulge in casual sex. Maluleke, 2007: 13) noted that the display and availability of condoms and exposure to some television programmes was viewed by parents as one of the factors motivating teenagers to want to engage in sexual intercourse.

\section{Recommendations}

Leininger's Sunrise Trans-Cultural Health Care Model (Leininger, 1991: 30) was used to develop recommendations as the model takes into consideration individuals and groups, their beliefs and value system. These specific cultural practices form the basis or the means through which the delivery of satisfactory health care to the people can be accomplished. The goal of this theory is to provide cultural congruent care. The three modes which guided these recommendations are: cultural care preservation or maintenance, cultural care repatterning or restructuring and cultural care accommodation (Leininger, 1991: 30).

\section{- $\quad$ Cultural care preservation or} maintenance

Although it is important for the parents to initiate dialogue on their own without any stimulus, it is still important for them to look out for physical and behavioural changes in the teenagers so as to initiate talk about issues of sexual health. Media is also a strong communicating tool and parents need to take radio and television discussions forward with teenagers. This will help them get used to the idea of talking to teenagers about sexual health. Use of initiation schools as places where teenagers can get more information about sexual health is also encouraged.

\section{- $\quad$ cultural care repatterning or restructuring}

Parents should by all means avoid use of indirect language when talking to teenagers about issues of sexual health as this can always lead to misinterpretation. Parents should not avoid situations which might assist them in engaging teenagers in a dialogue like television films as these may provide a good platform for initiating dialogue. They should also take responsibility for the education of their teenagers about sexual health. They should not push this responsibility to the schools or other members of the family. Parents should also explain to their teenagers about the use of condoms. These should not just be given without explanation.

\section{- cultural care accommodation}

Parents' expectations after talking to the teenagers about sexual health issues should be accommodated as it is always expected that teenagers behaviour should change. This means that teenagers will avoid unprotected sexual intercourse thus prevent infections and pregnancy.

\section{Limitations}

The researcher received a great deal of support from the chiefs in charge of the villages from which participants were drawn. It was also very easy to get the sample for the study. The participants were willing to be interviewed and the topic drew much interest from the group. However, the following were found to be limitations to the study. The empirical data was drawn from one district in Limpopo Province, and there- fore the findings can only be transferable within the district.

\section{Concluding remarks}

Data from parents indicate that they experience difficulties when they try to communicate with teenagers about issues of sexual health. It has been identified that cultural values and norms of the community stand in a way of communication between teenagers and parents. There is need for clarification of values to assist parents by easing the tensions related to sexuality education. Parents were also found to talk to their teenagers but by directing or telling them what to do or not to do. It was also identified that parents use indirect language when they communicate about sexual health with teenagers.

Use of indirect language confuses teenagers as their interpretations could be different from what the parents might think that they are communicating. It was also identified that parents have a difficulty in initiating a dialogue on sexual health. They indicated that they mostly start talking about sexual health after listening to radio programme or seeing something on television or observing physical changes on the teenagers. This was found not to be useful as teenagers might have started engaging in sex by the time that these observations are made.

\section{References}

BRINK, H I 2000: Fundamentals of research methodology for health professionals. Cape Town: Juta \& Company Ltd.

BROWN, JD; HALPERN, CT \& ENGLE, KL 2005: Mass media as a sexual super peer for early maturing girls. Journal for Adolescent Health, 36 (23): 420-427.

BURNS, N \& GROVE, S 2001: The practice of nursing research: conduct, critique and utilization. Philadephia: W. B Saunders.

CRESWELL, JW 1994: Research design: Qualitative and Quantitative approaches. London: SAGE publications.

EASTMAN, KL; CORONA, R \& SCHUSTER, MA 2006: Talking Parents, Healthy Teens: a worksite-based 
program for parents to promote adolescent sexual health. Preventing Chronic Disease. [On line] Available at: http://www.cdc.gov/ pcd/issues/2006/ oct/06_0012.htm

HALLOWAY, I \& WHEELER, S 1996: Qualitative research for nurses. Blackwell Science. Ltd. Australia.

HASSAN, EA \& CREATSAS, GC 2000: Adolescent Sexuality: A developmental milestone or risk-taking behavior? The role of health care in the prevention of sexually transmitted diseases. Journal of pediatric gynecology, 13(90): 119-124.

HE, K; KRAMER, E; HOUSER, RF; CHOMITZ, VR \& HACKER, KA 2004: Defining and understanding healthy lifestyle choices for adolescents. Journal for adolescent health, 35 (1): 26-33.

HOPKINS, A 2004: Teenage Pregnancy. Adolescence: Change and continuity. [Online].Available: http:// www.inside.bord.edu/academic/ specialprop/darling/adsex.htm

INGHAM, R \& STONE, N 2002: Factors affecting British teenagers contraceptive use at first intercourse. The importance of partner communication. Perspectives on Sexual and Reproductive Health. Academic Research Library. 34(4): 45-63.

KEMPNER, ME 2003: True integration of prevention programmes requires broad focus on sexual health. SIECUS report. Academic Research Library. 31 (3): p44-51.

KRISTEN, E; GIZLICE, Z; OWENO'DOWD, J; FOUST, E \& MILLER, C 2006: UNITED STATES: Parent opinion of sexuality education in a state with mandated abstinence education: Does policy match parental preferences? Journal of adolescent health. 39(5): 634-641.

KVALE, S 1983: The Qualitative Research Interview. A Phenomenological and a Hemeneutical mode of understanding. Journal of Phenomenological Psychology. 14(1): p171-196.

LEININGER, MM 1991: Cultural Care Diversity and Universality. A theory for Nursing. 350 Hunderson Street. New
York. National League of Nursing.

LINCOLN, Y \& GUBA, E 1885: Naturalistic inquiry. London: Sage Publication.

MAJA, T 2007: Involvement of males in promoting reproductive health. Curationis. 30 (1) p71-76.

MALULEKE, TX 2007: The youths' perceptions of sexuality in the Limpopo Province of South Africa. Health SA Gesondheid, 12(3): 3-16.

\section{MAVUNDLA, TR \& WILLIAMS, CX} 1999: Teenage mothers knowledge of sex education in general hospital of Umtata district. Curationis 22 (1) p5863.

MCCORMICKK, S 2004: Sexually Transmitted Diseases. Adolescence: Change and change. http:// www.inside.bord.edu/academic/ specialprop/darling/adsex.htm

MDLULI, M 2005. A psycho-educational model for facilitation of self discipline for educators in rural township schools. Unpublished Doctoral Thesis. UJ

MFONO, Z 1998: Teenage Contraceptive Needs in urban South Africa: A case Study. International Family Planning Perspective. Proquest Nursing Journals. 24 (4). p22-48.

MOUTON, J \& MARAIS, JC 1990: Methodology of the Social Sciences: Basic concepts. Pretoria: Human Research Council. (Unpublished D. Ed thesis). Johannesburg: RAU.

MOUTON, J 1996: Understanding Social Research. Pretoria: Van Schaiks.

MUELLER, TE; GAVIN, LE \& KULKARNI, A 2008: The association between sex education and youth engagement in sexual intercourse, Age at first intercourse and birth control use at first sex. Journal of adolescent health, 42(1): 89-96.

MULLER, KE \& POWERS, WG 1990: Parent-child sexual discussions: perceived communicator style and subsequent behavior. Adolescence. 25 (98) p469-482.
O'DONNELL, LO; STUEVE, A; DURAN, R; MYINT-U, A; AGRONICK, G; DOVAL, AS \& WILSON-SIMMONS, R 2008: Parenting Practices, Parents' Underestimation of Daughters' Risks, and Alcohol and Sexual Behaviors of Urban Girls. Journal of Adolescent Health, 42.(5): 496-502

POLIT, D \& HUNGLER, B 1995: Nursing research principles. USA. J.B Lippincot.

STYCOS, JM 1987: Attitudes of Costa Rican students and teachers on sex and population education. Perspect int planif fam. 1-6.

VUTTANONT, U; GREENHAIGH, TGM \& BOYTON, P 2006: "Smart boys and sweet girls" sex education needs in Thai teenagers: a mixed method study. The Lancet, 363 (9552): 2068-2080.

WOOD, K; MAFORAH, F \& JEWKES, R 1998: ' 'He forced me to love him”: Putting violence on adolescent sexual health agendas. Social Science Medicine, 47 (2): 233-242.

WULF, M 2004: Parents and children healthy conversation. Academic Research Library. 20 (5): p2-27. 